\title{
Результаты деятельности компаний в сфере туризма: роль стратегического предпринимательства
}

\author{
Муханад Хасан Ага ", Елена Гаффорова \\ Дальневосточный федеральный университет, г. Владивосток, Россия
}

Информация о статье

Поступила в редакиию:

24. 10.2020

Принята

к опубликованию:

16.11.2020

УДК 379.85; 65.012

JEL L26; Z32

\section{Ключевые слова:}

результаты деятельности компании, стратегическое предпринимательство, малый и средний бизнес, индустрия туризма, Приморский край

\section{Keywords:}

company performance, strategic entrepreneurship, small and medium-sized businesses, Tourism industry, the Primorey Territory

\begin{abstract}
Аннотация
В статье представлень результаты исследования компаний малого и среднего бизнеса в сфере туризма, работающих в Приморском крае. Для создания теоретической модели исследования были выявлены характеристики (переменные) концеециий предпринимательства, стратегического управления $и$ сотрудничества с конкурентами "coореtition» и рассмотрено их влияние на результать деятельности туристских компаний. Эмпирическая проверка гипотез исследования проводилась на базе данных 107 компаний. Полученные результать анализа свидетельствуют о положительной взаимосвязи между обеими компонентами стратегического предпринимательства (предпринимательство и стратегическое управление) с финансовыми и нефинансовыми показателями результатов деятельности туристских компаний. Результать анализа, также, указывают на положительное влияние сотрудничества с конкурентами «соореtition» и положительное влияние на его взаимодействие со стратегическим предпринимательством на финансовые и нефинансовые показатели результатов деятельности.
\end{abstract}

Companies Performance in Tourism: the Role of Strategic Entrepreneurship

Muhanad Hasan Agha, Elena Gafforova

\section{Abstract}

This article presents the results of the investigation of small and medium-sized tourism companies operating in the Primorey Territory. To create the theoretical model of the investigation, the characteristics (variables) of the entrepreneurship, strategic management and coopetition concepts were identified, and their impact on the performance of tourism companies was considered. Empirical testing of the research hypotheses was carried out on the database of 107 companies. The results of the

* Aвтор для связи: agha.muhanad@gmail.com DOI: https://dx.doi.org/10.24866/2311-2271/2020-3/21-44 
analysis show a positive relationship between both components of strategic entrepreneurship (entrepreneurship and strategic management) and the financial and non-financial performance indicators of the tourism companies. The results of the analysis also show the positive impact of coopetition and of its interaction with strategic entrepreneurship on the financial and non-financial performance indicators.

\section{Введение}

В последние годы туризм играет ключевую роль в мировой экономике. Развитие индустрии туризма стало источником значительных поступлений в иностранной валюте и поспособствовало созданию рабочих мест для многих стран [1].

По данным Всемирного совета по туризму и путешествиям (WTTC), в 2018 году прямой вклад туризма и путешествий в ВВП в мире составил 2750,7 млрд. долларов США (3,2\% от мирового ВВП), и прямо в туристском секторе было создано 122,891 млн. рабочих мест $(3,8 \%$ от общей занятости в мире). Общий вклад туристского сектора в мировой ВВП составил 8811,0 млрд. долларов США (10,4\% от мирового ВВП), а общий вклад сектора в занятость составил 318,811 млн. рабочих мест (10,0\% от общего трудоустройства в мире) в 2018 году [2].

Индустрия туризма характеризуется сочетанием различных по размеру фирм. С одной стороны, в ней представлены крупные компании, которые организуют массовые поездки и перевозки. Эти компании характеризуются своей способностью получать доступ к различным ресурсам, необходимым для своей деятельности, в дополнение к существующей системе управления [3]. В результате такие компании применяют различные стратегии для использования ресурсов и предоставления стандартных продуктов. С другой стороны, и в отличие от крупных, малые и средние туристские компании сталкиваются с проблемами получения финансирования, доступом к другим ресурсам, и характеризуются отсутствием управленческого опыта, что является препятствием для получения устойчивых результатов деятельности и дальнейшего развития.

Одним из направлений решения проблем малых и средних компаний в сфере туризма является совершенствование подходов к управлению, которые способствуют привлечению и использованию всех видов ресурсов и позволяют добиваться максимальной производительности в условиях их ограниченности.

Стратегическое управление и концепция предпринимательства используются менеджментом компаний для достижения положительных результатов и обеспечения роста компаний [4]. Возникшая в последние десятилетия управленческая концепция стратегического предпринимательства - это стремление компаний к достижению превосходных результатов за счет деятельности одновременно в двух направлениях: поиска возможностей (предпринимательство) и использования конкурентных преимуществ (стратегическое управление) [5]. Результаты исследования модели стратегического предпринимательства показывают положительную связь с результатами деятельности компаний малого и среднего бизнеса в разных отраслях [6]. 
Ketchen et al. [2007] утверждают, что, несмотря на то, что у малых предприятий могут быть сильные навыки поиска возможностей, их ограниченные запасы знаний, нехватка ресурсов и рыночной власти сдерживают их способность реализовывать конкурентные преимущества (эти ограничения сдерживают и использование открытых возможностей) [7].

Как отмечают многие исследователи, в туристской дестинации осуществляют деятельность множество независимых организаций, однако туристы, как правило, оценивают ее как единый продукт [3]. В такой ситуации малые и средние туристские фирмы вынуждены тесно сотрудничать, чтобы повысить общую конкурентоспособность дестинации в целом и обеспечить доходы своим компаниям [8]. Термин «сотрудничество с конкурентами» «coopetition» означает сочетание сотрудничества и конкуренции в действиях компании по отношению к другим фирмам на общем рынке [9]. Межорганизационное сотрудничество помогает туристским компаниям преодолевать нехватку отдельных ресурсов и, таким образом, оставаться конкурентоспособными в рамках общей дестинации [10].

Сотрудничество с конкурентами «соореtition» является ключевой стратегией компаний малого и среднего бизнеса, когда речь идет об использовании ограниченных ресурсов и удовлетворении потребностей туристов в целостном и индивидуально значимом опыте.

Цель нашей работы состоит в выявлении и оценке связи стратегического предпринимательства и результатов деятельности компаний малого и среднего бизнеса в сфере туризма, а также оценке возможности добавления «сотрудничества с конкурентами» «соореtition» в качестве дополнительной стратегии к созданию интегрированной модели управления в сфере туризма. К задачам исследования были отнесены: 1) анализ научных публикаций в сфере туризма для определения того, как исследователи изучали деятельность компаний с точек зрения: предпринимательства, стратегического управления и сотрудничества с конкурентами «соореtitin»; 2) формулирование и теоретическое обоснование гипотез исследования о характере связи отдельных и совместных компонентов стратегического предпринимательства, а также сотрудничества с конкурентами «соopetitin» с результатами деятельности компаний в сфере туризма; 3) характеристика методов исследования; 4) эмпирическая проверка гипотез; 5) описание и анализ полученных результатов. Для эмпирической проверки выдвинутых гипотез были использованы данные опроса компаний малого и среднего бизнеса в сфере туризма в Приморском крае в период с февраля по июль 2020г. В окончательную выборку вошли 107 компаний (58 туроператоров и 49 гостиниц).

\section{Теоретическая модель и гипотезы исследования}

Роль стратегического предпринимательства и сотрудничества с конкурентными «соореtition» в деятельности компаний сферы туризма

Деятельность компаний в сфере туризма как объект исследования представляет интерес для исследователей как в области предпринимательства, так и в областях стратегического управления и сотрудничества с конкурентами «coopetition». Для формирования перечня характеристик стратегического предпринимательства, необходимого для нашего исследования, были проана- 
лизированы научные публикации в сфере туризма для определения того, как исследователи изучали деятельность компаний с точек зрения: предпринимательства, стратегического управления и сотрудничества с конкурентами «coopetitin». На рис. 1 представлены основные результаты данного анализа.

С точки зрения предпринимательства многочисленные исследования показали, что личностные и демографические характеристики влияют на результаты предпринимательской деятельности $[11,12]$.

Туристская дестинация и ее составляющие являются источником разнообразных возможностей для предпринимателей. McGrath and MacMillan [2000] утверждают, что люди с острой предпринимательской настороженностью демонстрируют предпринимательский настрой. Они предполагают, что люди с предпринимательским мышлением, как правило, являются обычными предпринимателями, но имеют некоторые специфические общие черты. Среди них - страстное стремление к поиску возможностей, особое внимание к наиболее многообещающим из них, привлечение всех остальных, вовлеченных в поиск возможностей, и упор на их использование [13].

Исходя из мотивации, побуждающей к созданию новых предприятий, ученые классифицируют предпринимателей в основном на ориентированных на рост или ориентированных на образ жизни [14-16]. Ориентированные на рост предприниматели уверены в своей способности управлять бизнесом, имеют высокую склонность к риску и ценят творческие способы ведения дел. Их цель - развивать бизнес, который может конкурировать, расти и создавать рабочие места [16]. Предприниматели, ориентированные на образ жизни, больше внимания уделяют не максимизации прибыли, а улучшению качества своей жизни, живя в местах, которые им нравятся, создавая социальные связи, являясь частью сообщества $[14,15,11,17]$.

Некоторые исследования показывают, что не экономически мотивированные предприниматели совершенно не готовы к угрозам, исходящим из внешней среды из-за многих стратегических проблем, которые во многих случаях приводят к неудаче и закрытию [18]. В условиях динамичной внешней среды (какой и является туризм) выживают только группы предпринимателей с мотивами экономического роста, у которых доминируют предпринимательские установки, обуславливающие долгосрочное существование бизнеса [17]. Именно они, в первую очередь, определяют существующие и открывающиеся возможности и используют их для получения соответствующей потребительской ценности [19].

Исходя из вышеизложенного можно сделать вывод, что в нашем исследовании первой характеристикой (переменной) концепции предпринимательства является предпринимательское мышление. Предпринимательское мышление определяется как ориентированная на рост перспектива. Оно фокусируется на творческом подходе и усилиях по обновлению, направленных на выявление и развитие возможностей для нового бизнеса [5]. Это позволит туристской компании исследовать новые возможности, предлагаемые туристской дестинацией, в которой она работает, и пытаться использовать их. 


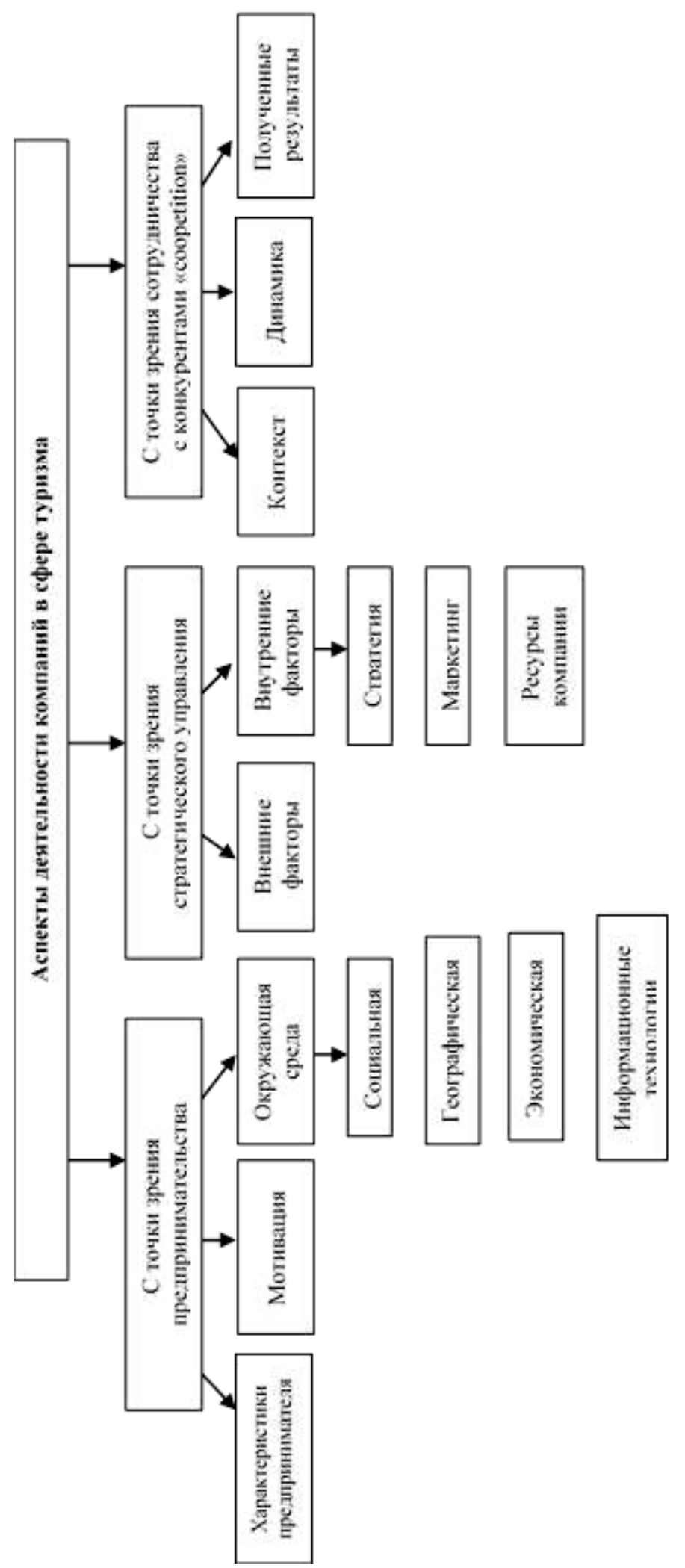

Puc. 1. Основные аспекты деятельности компаний в сфере туризма Источник: составлено авторами 
Наиболее важным моментом является то, как предприниматели действуют, чтобы адекватно оценить выявленные возможности и применить их. Это может проявляться в форме инвестирования в существующие направления, чтобы можно было использовать эти возможности позже. Или, скорее всего, в форме создания инноваций. Инновационная составляющая представляет собой средство, при помощи которого реализуется и применяется креативность в компании. Процесс инновационного предпринимательства может помочь компаниям использовать деловые возможности радикальным и прорывным способом [20].

Таким образом, можно сказать, что, второй характеристикой (переменной) концепции предпринимательства являются инновации.

С точки зрения стратегического управления значительное внимание исследователей уделяется взаимосвязи стратегического управления с результатами деятельности компаний. В исследованиях стратегического управления компаний существует консенсус в отношении того факта, что результаты организации могут зависеть от стратегии, принятой руководством (внутренние переменные), а также от ряда причин, в основном связанных со структурой рынка или сектора (внешние переменные) [21]. Тем не менее, можно считать, что внешние переменные (не контролируемые руководством) не получили большого внимания со стороны исследователей в области стратегического управления для объяснения различий в показателях деятельности компаний в секторе туризма [22].

С другой стороны исследования внутренних переменных получили большое внимание со стороны исследователей. Этот выбор в основном оправдывается большей простотой исследовательской стратегии, более прямой идентификацией отношений между зависимыми и независимыми переменными и большей важностью выводов для предприятий. На самом деле компании, особенно если это малый и средний бизнес, труднее воздействовать на внешние переменные своим поведением. В связи с этим исследователи изучили роль, которую ресурсы компании играют в качестве одной из внутренних переменных, влияющих на деятельность туристских компаний [23-25].

Стратегическое управление ресурсами включает в себя ряд действий для структурирования, объединения и использования имеющихся у компании ресурсов для формирования и фильтрации тех возможностей, которые уже были [26]. Это позволит туристской компании более эффективно использовать свои ресурсы и, следовательно, получать и поддерживать конкурентное преимущество. Конкурентное преимущество представляет собой степень, в которой организация способна создать защищаемую позицию над своими конкурентами, используя текущие преимущества в сочетании с новыми связками при поиске возможностей [5].

Таким образом, в нашем исследовании стратегическое управление ресурсами и конкурентные преимущества являются характеристиками (переменными) концепции стратегического управления.

Туристская дестинация действует как центр естественного сотрудничества с конкурентами «соореtition», который обеспечивает баланс между конкуренцией и сотрудничеством, развивая все заинтересованные стороны и повышая при этом эффективность самой дестинации. Сотрудничество с конку- 
рентами «соopetition» является совместным усилием конкурентов для взаимной выгоды [9]. Преимущества можно извлекать как из конкуренции, так и из сотрудничества. Разница заключается в том, что конкурентная сторона отношений не требует взаимной выгоды, тогда как сторона сотрудничества не может существовать без взаимной выгоды [27].

Многими исследователями обсужден контекст, который приводит к применению стратегии «соopetition» при работе с конкурентами в сфере туризма. Здесь появляются некоторые важные переменные, которые влияют на создание отношений сотрудничества с конкурентами, такие как тип промышленности [28], кооперативное мышление [29], предшественники сотрудничества с конкурентами «coopetition» [30]. Доверие очень важно во взаимных отношениях компаний [31]. В «coopetition» партнер развивает доверие в отношении того, как другая фирма будет делиться ресурсами, общаться, использовать информацию и другие аспекты сотруднического измерения отношений [27].

Особенностью отношений сотрудничества с конкурентами «coopetition» является то, что партнеры адаптируют свои процессы и продукты для достижения наилучшего соответствия друг другу, обмениваясь информацией и опытом, а также устраняя или сводя к минимуму источники небезопасности и неопределенности. Эту особенность можно назвать обязательством. Как функция, определяющая степень приверженности, она ведет к повышению уровня доверия для создания и укрепления текущих стратегических деловых отношений [32].

Точно так же доверие оказывает положительное влияние на взаимную выгоду, что, в свою очередь, влияет на успешность взаимоотношений [27]. Таким образом, аспекты сотрудничества с конкурентами «соореtition» (взаимная выгода, доверие и обязательства) должны взаимодействовать друг с другом, что определяет успешные отношения такого сотрудничества. Эти аспекты представляют собой основные характеристики (переменные) концепции сотрудничества с конкурентами «coopetition» для нашего исследования.

В итоге, на основании результатов контент-анализа научных публикаций была проведена авторская классификация характеристик деятельности компаний: а) с точки зрения предпринимательства (предпринимательское мышление и инновации), б) с точки зрения стратегического управления (стратегическое управление ресурсами и конкурентные преимущества), в) с точки зрения сотрудничества с конкурентами «соореtition» (взаимная выгода, доверие и обязательства).

\section{Предпринимательская составляющая стратегического предпринимательства и результаты деятельности компаний малого и среднего бизнеса в сфере туризма}

Компания, развившая предпринимательскую культуру, будет постоянно внедрять инновации, улучшать и находить новые способы увеличения прибыли и роста. Это особенно актуально для малых и средних туристских компаний, которые из-за ограниченных ресурсов должны постоянно искать новые возможности для инноваций, чтобы выжить и развиваться. Предпринимательское поведение является ключом к результатам финансовой деятельности туристских фирм [33]. 
Ученые находят доказательства того, что компании с предпринимательской ориентацией демонстрируют более высокий уровень результатов деятельности [34]. Именно так была доказана более высокая прибыльность компаний с более сильным предпринимательским потенциалом, чем у обычных фирм. Кроме того, авторами отмечается более быстрый рост фирм с внутренними предпринимательскими инициативами как их отличительными характеристиками [35].

С другой стороны, предпринимательская составляющая способствует улучшению различных организационных процессов, что, в свою очередь, влияет на результаты экономической деятельности фирм. Например, уровень инноваций (продукт, процесс, администрирование инноваций) зависит от уровня элементов корпоративного предпринимательства [36]. Многие источники указывают, что увеличение результатов производительности достигается путем разработки новых идей для продуктов и процессов компании [37]. Предпринимательские идеи становятся основой для развития новых видов деятельности в автономных организационных единицах за счет обновления портфеля продуктов / услуг фирмы и экспансии на новые рынки [38], что приводит к улучшению результатов деятельности компании и выражается в увеличении прибыли и ее росте.

Когда малые и средние туристские компании в состоянии распознать возможности и развить управленческую гибкость и креативность среди сотрудников, их подход к управлению становится конкурентным преимуществом в привлечении талантов и развитии лояльности персонала [39]. Это, в свою очередь, также приводит к устойчивому росту. На основании вышеизложенного можно сформулировать следующую гипотезу:

H1. Предпринимательская составляющая стратегического предпринимательства положительно связана с результатами деятельности малых и средних туристских компаний.

Стратегическая составляющая стратегического предпринимательства и результаты деятельности компаний малого и среднего бизнеса в сфере туризма

В то время как предпринимательство позволяет искать возможности, стратегическое управление ресурсами и внутрифирменные изменения позволяют фирме постоянно использовать существующие возможности для роста [40]. Стратегический компонент стратегического предпринимательства ориентирован на использование конкурентных преимуществ и стратегическое управление доступными ресурсами [6]. Эффективные стратегические действия рассматриваются как ключ к повышению конкурентоспособности компании [41], при этом, для поддержания конкурентоспособности (и размера прибыли), требуется эффективное управление корпоративными ресурсами.

Несмотря на утверждения, что существует тесная связь между стратегическим управлением и результатами деятельности фирмы, существует мнение, что эти две переменные не имеют прочных отношений [42]. Тем не менее, данные исследований сектора туризма показывают, что стратегическое управление оказывает позитивное влияние на организационные показатели [23]. На основании вышеизложенного можно сформулировать следующую гипотезу: 
H2. Стратегическая составляющая стратегического предпринимательства положительно связана с результатами деятельности малых и средних туристских компаний.

Синергетический эффект предпринимательского и стратегического компонентов стратегического предпринимательства и результаты деятельности компаний малого и среднего бизнеса в сфере туризма

Стратегическое предпринимательство включает в себя достижение баланса между поиском возможностей и выгодами для компаний [5] Поиск возможностей включает в себя сортировку потенциальных возможностей для определения областей будущей деятельности фирмы. Общий успех усилий по поиску возможностей зависит от того, как фирма поглощает и интегрирует новые и существующие знания. Их баланс повышает производительность, делая организацию инновационной, гибкой и эффективной, не теряя преимущества стабильности, установленных процедур и эффективности [43].

Мы считаем, что традиционные подходы к ведению бизнеса становятся менее приемлемыми в быстро растущей туристской бизнес среде. Отличительной чертой предпринимательских фирм является их способность распознавать новые возможности и реализовывать эти возможности быстрее, чем их конкуренты, и делая это, несмотря на ограниченные ресурсы [44]. В то же время необходимо развивать способность использования этих возможностей для достижения устойчивого конкурентного преимущества. Таким образом, мы предполагаем, что стратегическое предпринимательство в малых и средних туристских компаниях окажет положительное влияние на результаты их деятельности:

H3. Стратегическое предпринимательство оказывает положительное влияние на результаты деятельности малых и средних туристских компаний.

Сотрудничество с конкурентами «соореtition» и результаты деятельности компаний малого и среднего бизнеса в сфере туризма

Сотрудничество с конкурентами «соopetition» имеет несколько последствий. Оно может быть выгодным как с точки зрения рынка, так и с точки зрения эффективности инноваций [45].

Ritala and Tidström [2014] показывают, что сотрудничество с конкурентами может служить богатым источником возможностей для создания стоимости [46]. Кроме того, в условиях высокой конкуренции в отрасли сотрудничество с конкурентами может стать вынужденной стратегией для обеспечения возможностей выживания [47].

Bengtsson and Kock [2000] утверждают, что сотрудничество с конкурентами «соopetition», на самом деле, является наиболее взаимовыгодными отношениями для конкурентов [48]. Сотрудничество с конкурентами дает всем сторонам доступ к дополнительным ресурсам [9], разделяет затраты и риски неудач инновационных проектов [49].

В своем исследовании Ritala [2012] обсуждает, что «соopetition» может помочь компании: 1) увеличить размер существующего рынка компании или создать новые рынки (с помощью инноваций); 2) использовать меньше ресурсов или более эффективно использовать свои текущие ресурсы для обслужива- 
ния существующей доли рынка; 3) защитить долю рынка, которую компания смогла захватить, и завоевать большую долю того, что остается [45].

В контексте туризма сотрудничество с конкурентами «соopetition» предполагает две разные логики взаимодействия. С одной стороны, существует враждебность из-за противоречивых интересов получить большую часть бизнеса, когда посетители находятся в общей туристской дестинации; с другой стороны, необходимость объединять ресурсы и разрабатывать взаимные обязательства для достижения общей цели: привлечения посетителей в туристскую дестинацию [10].

Кроме того, Crick [2018] находит, что если отдельные организации (работающие в одной дестинации) будут продвигать свои товары и услуги как отдельные бренды, продажи будут низкими; однако, если группа конкурирующих брендов будет сотрудничать и проводить рекламные мероприятия (например, торговые выставки), клиенты будут более заинтересованы, что потенциально может улучшить продажи всех участвующих организаций [50].

Исходя из этого, можно сделать вывод, что сотрудничество с конкурентами «coopetition» могло бы повысить производительность всех компаний, занимающихся такой деятельностью [51]. Это приводит нас к формулировке следующей гипотезы:

H4. Сотрудничество с конкурентами «соopetition» оказывает положительное влияние на результаты деятельности малых и средних туристских компаний.

С другой стороны, у некоторых небольших организаций может быть так мало ресурсов и возможностей, что менеджеры не могут инвестировать активы своих фирм в стратегии, необходимые им для ведения бизнеса [52]. Таким образом, малые и средние туристские компании сотрудничают со своими конкурентами посредством совместного использования ресурсов и возможностей для достижения лучших результатов, чем если бы они работали на индивидуалистическом уровне [53, 46, 54]. Следовательно, сотрудничество с конкурентами направлено на то, чтобы помочь малым и средним туристским компаниям улучшить результаты своей деятельности способами, которые были бы невозможны без ресурсов и возможностей конкурентов $[48,45,50]$.

Кроме того, «coopetition» стратегии были выделены в качестве основных факторов, стимулирующих инновации, поскольку они позволяют компаниям разрабатывать новые продукты [55] и инновационные бизнесмодели [56], учиться у партнеров, делиться знаниями [57] и защищать инновации от подражания [45, 49].

Во многих случаях сотрудничество с конкурентами предлагает привлекательную стратегию для повышения конкурентоспособности фирмы и обеспечения успеха радикальных инноваций [57]. Соответственно, «coopetition» потенциально предлагает конкурентные преимущества, которые проистекают из способности компании разрабатывать продукты или услуги, которые она в одиночестве никогда не сможет разработать или на это потребуется слишком много времени [58].

Мы можем сделать вывод, что сотрудничество с конкурентами «coopetition» в качестве дополнительной стратегии улучшит стратегическую 
модель предпринимательства и поможет компаниям достичь наилучших результатов. Это приводит нас к формулировке следующей гипотезы:

H5. Стратегическое предпринимательство совместно с сотрудничеством с конкурентами «соopetition» оказывает положительное влияние на результаты деятельности малых и средних туристских компаний.

Теоретическая модель исследования представлена на рисунке 2.

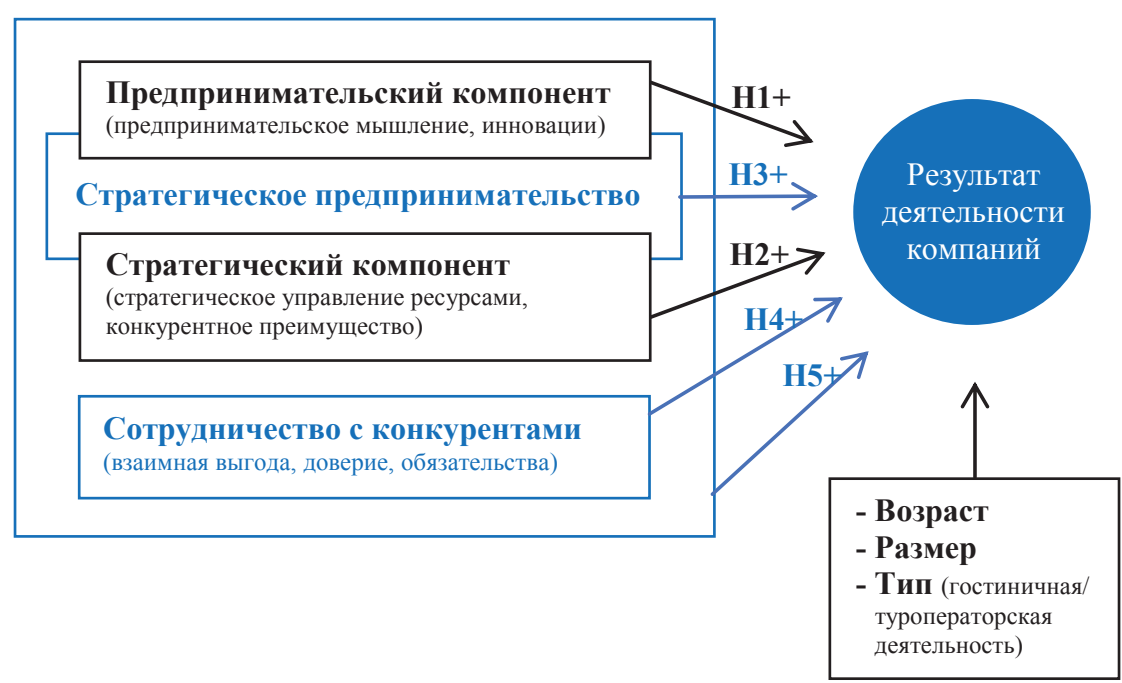

Puc. 2. Теоретическая модель связи стратегического предпринимательства с результатами деятельности компаний

Источник: составлено авторами

\section{Методология исследования}

Контекст исследования и описание выборки

Для проверки теоретической модели исследования мы провели эмпирическое исследование влияния отдельных и совместных компонентов модели на финансовые и нефинансовые результаты деятельности компаний малого и среднего бизнеса в сфере туризма в Приморском крае. Данные компаний были собраны в период с февраля по июль 2020 года. Респондентами выступили лица, ответственные за принятие ключевых решений в компании: представители топ-менеджмента и владельцы туристских фирм Приморского края.

Список частных российских предприятий выборки был случайным образом сгенерирован на базе основных государственных регистрационных номеров (ОГРН). Затем коды ОГРН были загружены в систему профессионального анализа рынков и компаний (СПАРК-Интерфакс) для проверки их достоверности, сбора информации о компаниях и их ключевых финансовых показателях, а также фильтрации сведений, соответствующих критериям отбора, принятым в нашем исследовании. Выборка включает в себя компании с критериями размера от 1 до 250 сотрудников и возрастом не менее 3 лет (по- 
скольку столь малый возраст не позволяет фирмам в полной мере реализовывать стратегию). В конечную выборку вошли 179 компании.

Сбор данных осуществлялся посредством онлайн-анкетирования. Заполненные 111 анкет из 162, функционирующих и желающих принять участие в опросе компаний, означают, что эффективная доля ответивших составила $68.5 \%$. После очистки данных от пропущенных значений в окончательной выборке оказалась 107 (58 туроператоров и 49 гостиниц) компаний.

Преобладающая доля компаний выборки относятся к категории микробизнеса (81 компания) с численностью персонала не более 15 человек.

\section{Измерение переменных}

\section{Зависимая переменная}

Переменная «результаты деятельности компаний» представляет собой субъективный показатель, измеренный с помощью 5-бальных шкал Лайкерта (одна для финансовых, а вторая для нефинансовых результатов деятельности компаний), использованных в работе Avci et al., [2011] [59]. Значение их альфа Кронбаха составляет 0,734 и 0,721 соответственно, а конечные значения рассчитаны как средние для всех компонентов каждой мультипеременной.

\section{Независимые переменные}

Предпринимательский компонент стратегического предпринимательства рассчитан как среднее значение показателей «предпринимательское мышление» и «инновации». Оба показателя были измерены с помощью 7-балльной шкалы Лайкерта, использованной в работе [6]. Альфа Кронбаха предпринимательского компонента в целом составила 0.919 .

Стратегический компонент стратегического предпринимательства рассчитан как среднее значение показателей «стратегическое управление ресурсами» и «конкурентное преимущество». Оба были измерены с помощью той же 7-балльной шкалы Лайкерта, что и в предыдущем случае. Альфа Кронбаха стратегического компонента в целом составила 0.720 .

Чтобы стандартизировать статистику, мы конвертировали шкалу Лайкерта из 7-балльной в обеих шкалах (предпринимательского и стратегического компонентов) в 5-балльную шкалу, как это было предложено Dawes [2008] [60].

Сотрудничество с конкурентами «Coopetition» рассчитано как среднее значение показателей «взаимная выгода», «доверие» и «обязательства». Все показатели были измерены с помощью 5-балльной шкалы Лайкерта, использованной в работе Morris et al. [2007] [27]. Альфа Кронбаха сотрудничества с конкурентами «соopetition» в целом составила 0.930.

Для обеспечения внутренней валидности были использованы такие контрольные переменные, как возраст компании, ее размер и тип компании (гостиничная или туроператорская деятельность).

Описательная статистика и корреляционная матрица приведены в табл. 1, и регрессионные модели исследования с расшифровкой основных переменных приведены в табл. 2. 
Таблица 1

Описательная статистика и корреляционная матрица переменных

\begin{tabular}{|c|c|c|c|c|c|c|c|c|c|c|c|c|}
\hline & $\begin{array}{l}\text { Сред. } \\
\text { знач }\end{array}$ & $\begin{array}{l}\text { Станд. } \\
\text { откл. }\end{array}$ & $\begin{array}{l}\text { Мин. } \\
\text { знач. }\end{array}$ & $\begin{array}{l}\text { Макс. } \\
\text { знач. }\end{array}$ & 1 & 2 & 3 & 4 & 5 & 6 & 7 & 8 \\
\hline 1. Размер компании & 1.26 & 0.482 & 1 & 3 & 1 & & & & & & & \\
\hline 2. Возраст компании & 13.21 & 6.827 & 3 & 53 & .066 & 1 & & & & & & \\
\hline 3. Тип компании & 0.46 & 0.501 & 0 & 1 & $.554 * *$ & .115 & 1 & & & & & \\
\hline $\begin{array}{l}\text { 4. Предприниматель- } \\
\text { ский компонент }\end{array}$ & 3.84 & 1.067 & 1 & 5 & .049 & $-192 *$ & .146 & 1 & & & & \\
\hline $\begin{array}{l}\text { 5. Стратегический } \\
\text { компонент }\end{array}$ & 3.61 & 0.772 & 1.50 & 4.75 & -.083 & $.210^{*}$ & -.080 & $.366^{* * *}$ & 1 & & & \\
\hline $\begin{array}{l}\text { 6. Сотрудничество с } \\
\text { конкурентами } \\
\text { «coopetition» }\end{array}$ & 3.75 & 0.772 & 2.20 & 4.60 & -.065 & .040 & -.042 & $.226^{*}$ & $.688^{* *}$ & 1 & & \\
\hline 7. Финансовые факторы & 3.58 & 0.986 & 1.25 & 5 & .102 & -.031 & $.237 *$ & $.580^{* 1 m}$ & $.743^{m+1}$ & $.722^{* 1 *}$ & 1 & \\
\hline $\begin{array}{l}\text { 8. Нефинансовые фак- } \\
\text { торы }\end{array}$ & 3.63 & 0.769 & 2 & 4.60 & -.080 & -.015 & -.002 & $.466^{* *}$ & $.652^{* *}$ & $.637^{* *}$ & $.756^{* *}$ & 1 \\
\hline
\end{tabular}

Примечание: $\mathrm{n}=107$

** Correlation is significant at the 0.01 level (2-tailed).

* Correlation is significant at the 0.05 level (2-tailed).

Источник: составлено авторами

Таблица 2

Регрессионные модели, влияющие на результаты деятельности компаний

\begin{tabular}{|c|c|}
\hline \multicolumn{2}{|r|}{ Регрессионные модели влияния на финансовые показатели } \\
\hline Модели & Уравнение регрессии \\
\hline Модель 1 & $\mathrm{Y}_{\mathrm{i}}^{\mathrm{f}}=b_{0}+b_{1} \times S I Z E_{i}+b_{2} \times A G E_{i}+b_{3} \times T Y P E_{i}$ \\
\hline Модель 2 & $\mathrm{Y}_{\mathrm{i}}^{\mathrm{f}}=b_{0}+b_{1} \times S I Z E_{i}+b_{2} \times A G E_{i}+b_{3} \times T Y P E_{i}+b_{4} \times \mathrm{ENT}_{\mathrm{i}}+b_{5} \times \mathrm{STR}_{\mathrm{i}}$ \\
\hline Модель 3 & $\begin{aligned} \mathrm{Y}_{\mathrm{i}}^{\mathrm{f}}= & b_{0}+b_{1} \times S I Z E_{i}+b_{2} \times A G E_{i}+b_{3} \times T Y P E_{i}+b_{4} \times \mathrm{ENT}_{\mathrm{i}}+b_{5} \times \mathrm{STR}_{\mathrm{i}}+b_{4} \times b_{5} \times \mathrm{ENT}_{\mathrm{i}} \times \\
& \times \mathrm{STR}_{\mathrm{i}}\end{aligned}$ \\
\hline Модель 4 & $\begin{aligned} \mathrm{Y}_{\mathrm{i}}^{\mathrm{f}}= & b_{0}+b_{1} \times \mathrm{SIZE}_{i}+b_{2} \times A G E_{i}+b_{3} \times T Y P E_{i}+b_{4} \times \mathrm{ENT}_{\mathrm{i}}+b_{5} \times \mathrm{STR}_{\mathrm{i}}+b_{6} \times \mathrm{COOP}_{\mathrm{i}}+b_{4} \times \\
& \times b_{5} \times \mathrm{ENT}_{\mathrm{i}} \times \mathrm{STR}_{\mathrm{i}}\end{aligned}$ \\
\hline Модель 5 & $\mathrm{Y}_{\mathrm{i}}^{\mathrm{f}}=b_{0}+b_{1} \times S I Z E_{i}+b_{2} \times A G E_{i}+b_{3} \times T Y P E_{i}+b_{4} \times \mathrm{ENT}_{\mathrm{i}}+b_{5} \times \mathrm{STR}_{\mathrm{i}}+b_{6} \times \mathrm{COOP}_{\mathrm{i}}$ \\
\hline Модель 6 & $\begin{aligned} \mathrm{Y}_{\mathrm{i}}^{\mathrm{f}}= & b_{0}+b_{1} \times S I Z E_{i}+b_{2} \times A G E_{i}+b_{3} \times T Y P E_{i}+b_{4} \times \mathrm{ENT}_{\mathrm{i}}+b_{5} \times \mathrm{STR}_{\mathrm{i}}+b_{6} \times \mathrm{COOP}_{\mathrm{i}}+b_{4} \times \\
& \times b_{5} \times b_{6} \times \mathrm{ENT}_{\mathrm{i}} \times \mathrm{STR}_{\mathrm{i}} \times \mathrm{COOP}_{\mathrm{i}}\end{aligned}$ \\
\hline Модель 7 & $\begin{aligned} \mathrm{Y}_{\mathrm{i}}^{\mathrm{f}}= & b_{0}+b_{1} \times \operatorname{SIZE}_{i}+b_{2} \times A G E_{i}+b_{3} \times T Y P E_{i}+b_{4} \times b_{5} \times \mathrm{ENT}_{\mathrm{i}} \times \mathrm{STR}_{\mathrm{i}}+b_{4} \times b_{6} \times \mathrm{ENT}_{\mathrm{i}} \times \\
& \times \mathrm{COOP}_{\mathrm{i}}+b_{5} \times b_{6} \times \mathrm{STR}_{\mathrm{i}} \times \mathrm{COOP}_{\mathrm{i}}\end{aligned}$ \\
\hline \multicolumn{2}{|r|}{ Регрессионные модели влияния на нефинансовые показатели } \\
\hline Модели & равнение регрессии \\
\hline Модель 8 & $\mathrm{Y}_{\mathrm{i}}^{\mathrm{nf}}=b_{0}+b_{1} \times S I Z E_{i}+b_{2} \times A G E_{i}+b_{3} \times T Y P E_{i}$ \\
\hline Модель 9 & $\mathrm{Y}_{\mathrm{i}}^{\mathrm{nf}}=b_{0}+b_{1} \times S I Z E_{i}+b_{2} \times A G E_{i}+b_{3} \times T Y P E_{i}+b_{4} \times \mathrm{ENT}_{\mathrm{i}}+b_{5} \times \mathrm{STR}_{\mathrm{i}}$ \\
\hline Модель 10 & $\begin{aligned} \mathrm{Y}_{\mathrm{i}}^{\mathrm{nf}}= & b_{0}+b_{1} \times S I Z E_{i}+b_{2} \times A G E_{i}+b_{3} \times T Y P E_{i}+b_{4} \times \mathrm{ENT}_{\mathrm{i}}+b_{5} \times \mathrm{STR}_{\mathrm{i}}+b_{4} \times b_{5} \times \mathrm{ENT}_{\mathrm{i}} \times \\
& \times \mathrm{STR}_{\mathrm{i}}\end{aligned}$ \\
\hline Модель 11 & $\begin{aligned} \mathrm{Y}_{\mathrm{i}}^{\mathrm{nf}}= & b_{0}+b_{1} \times \mathrm{SIZE}_{i}+b_{2} \times A G E_{i}+b_{3} \times T Y P E_{i}+b_{4} \times \mathrm{ENT}_{\mathrm{i}}+b_{5} \times \mathrm{STR}_{\mathrm{i}}+b_{6} \times \mathrm{COOP}_{\mathrm{i}}+ \\
& +b_{4} \times b_{5} \times \mathrm{ENT}_{\mathrm{i}} \times \mathrm{STR}_{\mathrm{i}}\end{aligned}$ \\
\hline Модель 12 & $\mathrm{Y}_{\mathrm{i}}^{\mathrm{nf}}=b_{0}+b_{1} \times S I Z E_{i}+b_{2} \times A G E_{i}+b_{3} \times T Y P E_{i}+b_{4} \times \mathrm{ENT}_{\mathrm{i}}+b_{5} \times \mathrm{STR}_{\mathrm{i}}+b_{6} \times \mathrm{COOP}_{\mathrm{i}}$ \\
\hline Модель 13 & $\begin{aligned} \mathrm{Y}_{\mathrm{i}}^{\mathrm{nf}}= & b_{0}+b_{1} \times S I Z E_{i}+b_{2} \times A G E_{i}+b_{3} \times T Y P E_{i}+b_{4} \times \mathrm{ENT}_{\mathrm{i}}+b_{5} \times \mathrm{STR}_{\mathrm{i}}+b_{6} \times \mathrm{COOP}_{\mathrm{i}}+ \\
& +b_{4} \times b_{5} \times b_{6} \times \mathrm{ENT}_{\mathrm{i}} \times \mathrm{STR}_{\mathrm{i}} \times \mathrm{COOP}_{\mathrm{i}}\end{aligned}$ \\
\hline Модель 14 & $\begin{aligned} \mathrm{Y}_{\mathrm{i}}^{\mathrm{nf}}= & b_{0}+b_{1} \times S_{Z} E_{i}+b_{2} \times A G E_{i}+b_{3} \times T Y P E_{i}+b_{4} \times b_{5} \times \mathrm{ENT}_{\mathrm{i}} \times \mathrm{STR}_{\mathrm{i}}+b_{4} \times b_{6} \times \mathrm{ENT}_{\mathrm{i}} \times \\
& \times \mathrm{COOP}_{\mathrm{i}}+b_{5} \times b_{6} \times \mathrm{STR}_{\mathrm{i}} \times \mathrm{COOP}_{\mathrm{i}}\end{aligned}$ \\
\hline \multicolumn{2}{|c|}{ 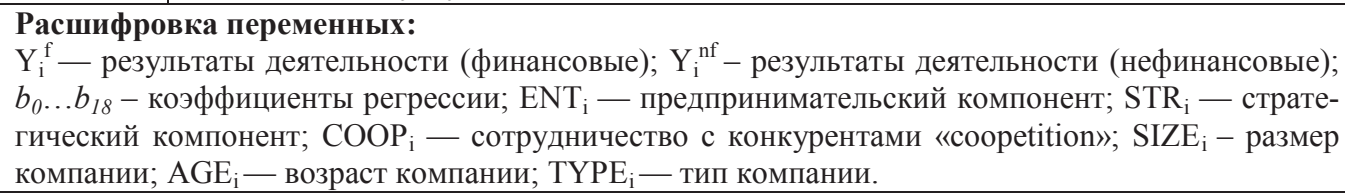 } \\
\hline
\end{tabular}

Источник: составлено авторами 


\section{Результаты анализа данных}

Поскольку в данном исследовании основные переменные модели были измерены с помощью субъективных оценок одних и тех же респондентов, была проведена оценка возможной общей ошибки смещения (common method bias) [61]. Для дополнительной надежности был применен тест Хармана (Harman's statistical test). Факторный анализ главных компонентов (principal component factor analysis) со всеми переменными модели выявил 13 главных компонентов с собственными значениями факторов (eigenvalues) больше 1 , а дисперсия, объясненная первым фактором, составила $33.297 \%$. Существование более одного фактора, ни на один, из которых не приходится более половины дисперсии, указывает на отсутствие общей ошибки смещения. В итоге общая ошибка смещения не является проблемой в настоящем исследовании.

Результаты тестирования гипотез с помощью регрессионного анализа, проведенного в несколько этапов, представлены в табл. 3 (модели 1-7 для результатов финансовой деятельности и модели 8-14 для результатов нефинансовой деятельности). Сначала была рассмотрена базовая модель, в которую вошли все контрольные переменные (модель 1 для результатов финансовой деятельности и модель 8 для результатов нефинансовой деятельности). В последующем были добавлены независимые переменные «предпринимательский компонент» и «стратегический компонент» (модель 2 для результатов финансовой деятельности и модель 9 для результатов нефинансовой деятельности). Объединенный показатель этих переменных отражен в моделях 3 и 10 (для результатов финансовой и нефинансовой деятельности соответственно).

Далее была добавлена независимая переменная «сотрудничество с конкурентами «coopetition»»" в моделях 4 и 11 (для результатов финансовой и нефинансовой деятельности соответственно). Сводный показатель «Развитое стратегическое предпринимательство», который объединяет переменную «предпринимательский компонент» с переменной «стратегический компонент» и с переменной «сотрудничество с конкурентами «соopetition», отражен в модели 6 (для результатов финансовой деятельности) и модели 13 (для результатов нефинансовой деятельности).

Результаты анализа базовых моделей исследования (модели 1 и 8), включающей контрольные переменные, показали, что тип компании положительно связан с финансовыми результатами деятельности. Это означает, что в случае, если туристская компания является гостиницей, ее финансовые результаты будут лучше, чем если бы она была туроператором $(\mathrm{b}=0,512$, $\mathrm{p}<0,05)$. Влияние размера и возраста компании на финансовые и нефинансовые результаты деятельности было незначительным. 
М. Хасан Ага, Е.Б. Гаффорова // Известия ДВФУ. Экономика и управление. 3. 2020. 21-44

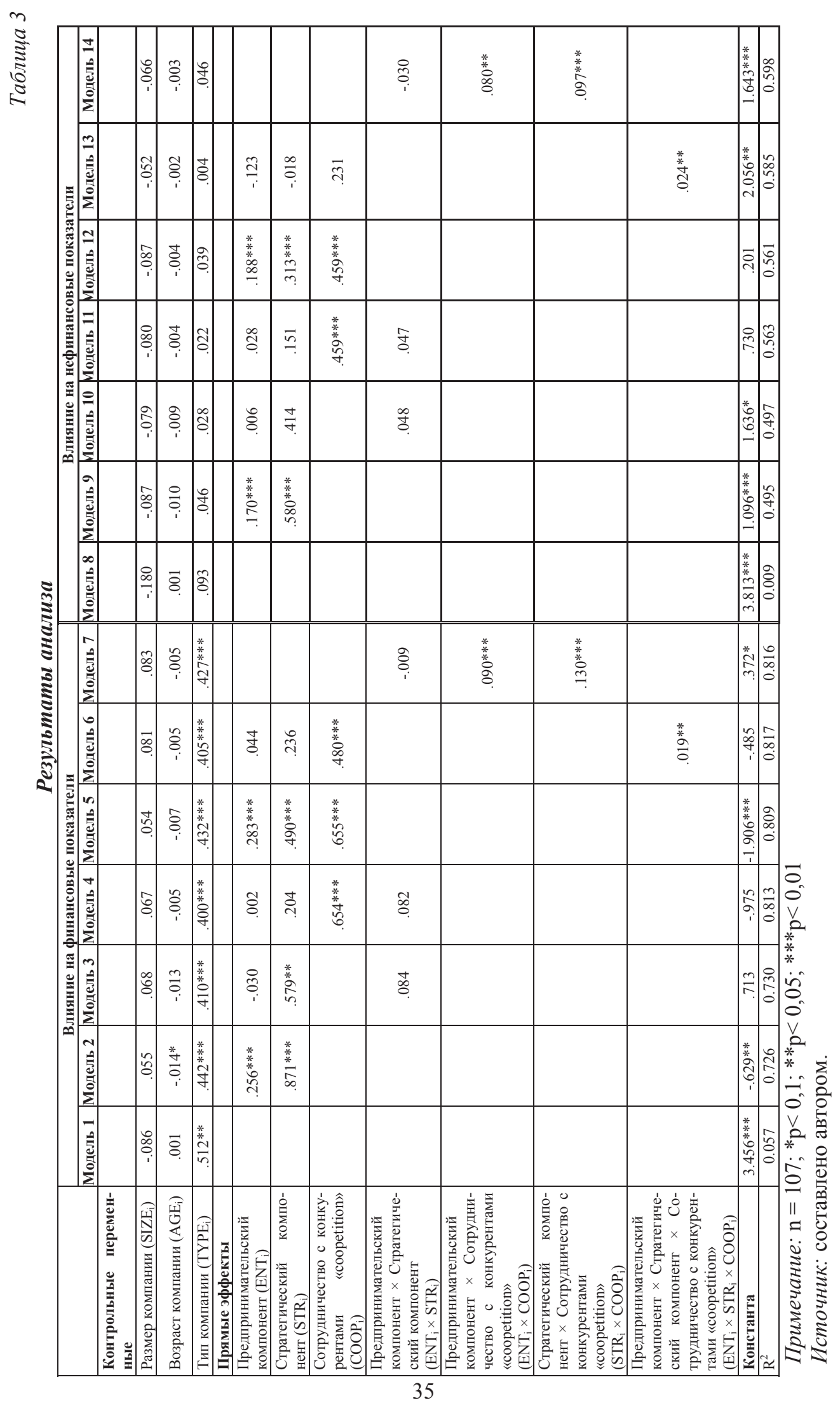


Гипотезы Н1 и Н2, свидетельствующие о положительном влиянии компонентов стратегического предпринимательства (предпринимательский и стратегический компоненты) на финансовые и нефинансовые результаты деятельности туристских фирм в Приморском крае, были проверены в моделях 2 и 9. Результаты анализа показали, что чем больше предпринимательства применяет туристская компания, тем лучше результаты ее финансовых показателей $(\mathrm{b}=0,256, \mathrm{p}<0,01)$ и нефинансовых показателей $(\mathrm{b}=0,170, \mathrm{p}<0,01)$. В результате видно, что предпринимательство имеет более прочную связь с результатами финансовой деятельности. Результаты анализа также показали, что чем больше туристской компанией применяется стратегическое управление, тем лучше будут ее финансовые результаты $(\mathrm{b}=0,871, \mathrm{p}<0,01)$ и результаты нефинансовой деятельности $(\mathrm{b}=0,580, \mathrm{p}<0,01)$. В результате видно, что стратегическое управление имеет более сильную связь с результатами финансовой деятельности. Поэтому туристская компания Приморского края получит выгоду от использования предпринимательского и стратегического компонентов, что позволяет подтвердить гипотезы Н1 и Н2.

Гипотеза Н3, предполагающая положительное влияние стратегического предпринимательства на результаты деятельности туристской фирмы в Приморском крае, была проверена в моделях 3 и 10. Результаты анализа показали, что влияние стратегического предпринимательства на финансовые и нефинансовые результаты деятельности туристской компании в Приморском крае не получило статистической поддержки. Полученный результат не подтверждает гипотезу Н3.

Гипотеза H4, предполагающая положительное влияние сотрудничества с конкурентами «соopetition» на результаты деятельности туристской компании в Приморском крае, была проверена в моделях 4 и 11. Результаты анализа показали, что чем больше туристская компания применяет сотрудничество с конкурентами «соopetition», тем лучше результаты ее финансовых показателей $(\mathrm{b}=0,654, \mathrm{p}<0,01)$ и результаты нефинансовой деятельности $(\mathrm{b}=0,459, \mathrm{p}<0,01)$.

Чтобы дополнительно подтвердить гипотезу, мы создали модели 5 и 12 (для результатов финансовой и нефинансовой деятельности соответственно). Для их получения в модели 2 и 9 (в которые вошли предпринимательский компонент и стратегический компонент стратегического предпринимательства без их объединенного показателя) была добавлена переменная «сотрудничество с конкурентами «соореtition»». В свою очередь, результаты анализа этих моделей подтвердили полученный результат ( $\mathrm{b}=0,655$, $\mathrm{p}<0,01$ для результатов финансовой деятельности) и $(\mathrm{b}=0,459, \mathrm{p}<0,01$ для результатов нефинансовой деятельности). Основываясь на этих обсуждениях, мы можем подтвердить гипотезу Н4, которая утверждает, что туристская компания в Приморском крае получит выгоду от применения сотрудничества с конкурентами «соopetition».

Гипотеза Н5, предполагающая положительное влияние развитого стратегического предпринимательства (в сочетании со стратегическим предпринимательством и сотрудничеством с конкурентами «соopetition») на результаты деятельности туристской фирмы в Приморском крае, была проверена в моделях 6 и 13. Результаты анализа показали, что чем более развито страте- 
гическое предпринимательство туристской компании, тем лучше ее финансовые результаты $(b=0,019, \mathrm{p}<0,05)$ и результаты нефинансовой деятельности $(\mathrm{b}=0,024, \mathrm{p}<0,5)$. Поэтому туристская компания в Приморском крае получит выгоду от применения новой модели стратегического предпринимательства, что позволяет подтвердить гипотезу Н5.

Чтобы понять взаимодействие между сотрудничеством с конкурентами, «coopetition», с одной стороны, и стратегическим предпринимательством, с другой, мы создали модели 7 и 14 (для результатов финансовой и нефинансовой деятельности соответственно). В этих двух моделях были созданы два новых показателя: один в результате взаимодействия между предпринимательским компонентом и сотрудничеством с конкурентами «соореtition», а второй в результате взаимодействия между стратегическим компонентом и сотрудничеством с конкурентами «соopetition». Их влияние изучалось при наличии стратегического предпринимательства (объединенный показатель предпринимательской и стратегической составляющих стратегического предпринимательства). Результаты анализа свидетельствуют о том, что чем больше взаимодействие предпринимательской составляющей с сотрудничеством с конкурентами «coopetition» в туристской компании Приморского края, тем лучше будут результаты ее финансовых $(\mathrm{b}=0,090, \mathrm{p}<0,01)$ и нефинансовых $(\mathrm{b}=0,080$, $\mathrm{p}<0,05)$ показателей. То же самое можно сказать и о взаимодействии стратегической составляющей с сотрудничеством с конкурентами «соopetition», в этом случае результаты ее финансовых и нефинансовых показателей будут $(b=0,130$, $\mathrm{p}<0,01)$ и $(\mathrm{b}=0,097, \mathrm{p}<0,01)$ соответственно.

Результаты эмпирического анализа малых и средних туристских компаний Приморского края свидетельствуют о положительной взаимосвязи между компонентами стратегического предпринимательства с финансовыми и нефинансовыми показателями деятельности туристских компаний. Результаты анализа, также, указывают на положительное влияние сотрудничества с конкурентами «соopetition» и его взаимодействия со стратегическим предпринимательством, что приводит нас к созданию комплексной модели стратегического предпринимательства в сфере туризма (рис. 3).

\section{Обсуждение полученных результатов}

Изучение взаимосвязи стратегического предпринимательства и его компонентов (в частности, предпринимательского и стратегического), а также сотрудничества с конкурентами «соореtition» с результатами деятельности компаний малого и среднего бизнеса в сфере туризма в Приморском крае позволило прийти к следующим выводам.

Предпринимательский компонент стратегического предпринимательства положительно связан с финансовыми и нефинансовыми показателями деятельности туристских компаний. С точки зрения ресурсов [62] и динамических способностей [63] предпринимательское мышление и инновация, как аспекты предпринимательства, можно рассматривать как особый организационный потенциал (нематериальные активы) [64]. 


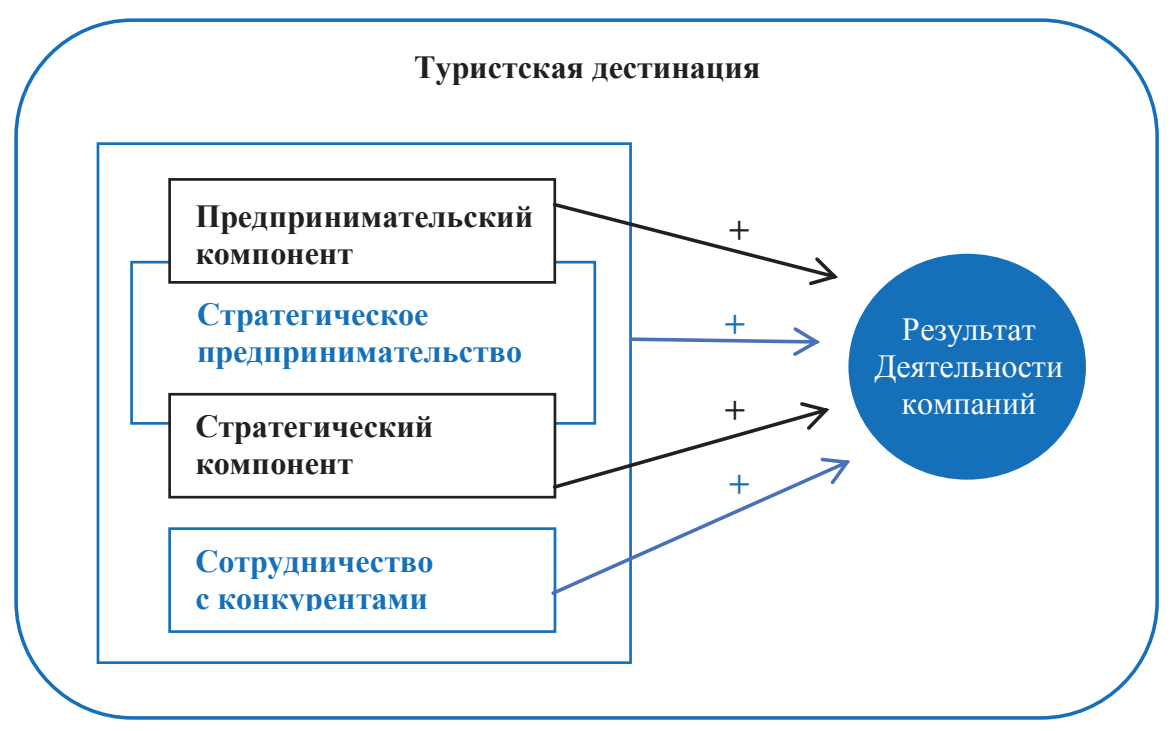

Puc. 3. Модель стратегического предпринимательства в сфере туризма Источник: составлено авторами

Развитие предпринимательского мышления позволяет компании исследовать и использовать новые возможности для бизнеса с помощью инноваций, что приводит к получению конкурентного преимущества и улучшению результатов деятельности [65]. Следовательно, развитие предпринимательства в туристской компании поможет ей наилучшим образом использовать окружающую среду, исследуя возможности и используя их для достижения конкурентного преимущества.

Стратегический компонент стратегического предпринимательства положительно связан с финансовыми и нефинансовыми показателями деятельности туристских компаний. Стратегическое управление ресурсами лежит в основе точки зрения динамических возможностей [66]. Стратегическое управление ресурсами позволяет компаниям более эффективно объединять имеющиеся ресурсы и привлекать новые. Тем самым позволяя им, получать более конкурентные преимущества [67]. Это означает, что развитие стратегического управления в туристской компании поможет ей достичь оптимального использования ресурсов и, таким образом, достичь конкурентного преимущества, а затем сохранить его.

Стратегическое предпринимательство не обнаруживает статистически значимой связи с финансовыми и нефинансовыми показателями деятельности туристских компаний.

Результаты эмпирического анализа показывают, что сотрудничество с конкурентами «соореtition» оказывает положительное влияние на финансовые и нефинансовые результаты деятельности туристской компании. Сотрудничество с конкурентами «соopetition» позволяет получить доступ ко многим жизненно важным ресурсам, которые обычно находятся вне контроля компании. Это позволяет компании получать доступ к ресурсам конкурентов, что приводит к предоставлению ценных ресурсов для стратегиче- 
ского использования и, таким образом, получения конкурентного преимущества [68]. С другой стороны, тот факт, что туристы рассматривают туристскую дестинацию как один интегрированный продукт, заставляет заинтересованные стороны сотрудничать друг с другом, чтобы создать продукт, который удовлетворит туристов [3]. Это побудит туристов продвигать регион в своих сообществах, что в целом увеличит турпоток в будущем и будет способствовать достижению лучших результатов деятельности для всех заинтересованных сторон. Сотрудничество с конкурентами «соopetition» помогает туристской компании решать проблемы ограниченных производственных линий, слабых человеческих ресурсов, скромных технологических возможностей и недостаточных денежных резервов [69]. Также, это будет способствовать оживлению эффективности управления.

Развитое стратегическое предпринимательство (в сочетании со стратегическим предпринимательством и сотрудничеством с конкурентами «coopetition») положительно связано с финансовыми и нефинансовыми показателями деятельности туристских компаний. Сочетание стратегического предпринимательства и сотрудничества с конкурентами «соopetition» в рамках новой модели стратегического предпринимательства позволит компании обладать целым рядом ресурсов и динамических возможностей (материальных и нематериальных активов) как внутри компании, так и за ее пределами. Предпринимательское мышление позволит предпринимателям раскрыть возможности туристской дестинации, а затем управлять стратегическими ресурсами, которыми владеет компания, и приступить к использованию возможностей, исследованных параллельно с использованием инноваций для предоставления уникальных продуктов и помощи в усилиях компании по достижению конкурентного преимущества [6]. Стратегическое предпринимательство обеспечивает основу, в которой эти ресурсы взаимодействуют для достижения устойчивого конкурентного преимущества, что отражается на результатах деятельности компании [5]. Изучение стратегического предпринимательства не получило достаточного внимания со стороны исследователей в области туризма, однако исследования подтвердили большое значение компонентов стратегического предпринимательства в отдельности [12]. Мы считаем, что развитие стратегического предпринимательства в туристских компаниях позволило бы предпринимателям преодолеть многие проблемы, связанные с нехваткой ресурсов, благодаря большой роли, которую играют динамические возможности (инновации и предпринимательское мышление) в дополнение к стратегическому управлению ресурсами. Путем объединения и взаимодействия этих активов, туристская компания сможет добиться максимальных результатов несмотря на ограниченные ресурсы, которыми она обладает, что положительно отразится на результатах ее деятельности.

\section{Заключение}

Чтобы определить роль, которую стратегическое предпринимательство может играть в качестве управленческого поведения для туристских компаний, и разработать интегрированную модель, соразмерную с характеристиками этих компаний и характером туристской деятельности в целом, это исследование охватило важные компоненты стратегического предпринимательства 
в направлениях предпринимательства и стратегического управления. Помимо изучения роли сотрудничества с конкурентами необходимо адаптировать стратегическое предпринимательство к характеристикам индустрии туризма и выстроить эффективную модель управления туристскими компаниями.

Теоретическая новизна проведенного нами исследования заключается в теоретическом обосновании и экспериментальной проверке характеристик взаимосвязи между стратегическим предпринимательством и сотрудничеством с конкурентами «соopetition» с результатами деятельности малых и средних компаний в сфере туризма.

Результаты исследования могут представлять интерес руководителей высшего звена, владельцев бизнеса и предпринимателей, работающих в сфере туризма. Результаты данного исследования могут быть использованы в практике менеджмента при выборе компонентов предпринимательства и компонентов стратегического управления для развития стратегического предпринимательства компании в сфере туризма. Руководители туристских компаний должны уделять внимание и работать над развитием элементов предпринимательства в компании. Директора компаний, также, должны уделять внимание инвестированию в принадлежащие им ресурсы и пытаться добиться оптимального их использования, что приведет к повышению конкурентного преимущества компании. С другой стороны, руководителям туристских компаний необходимо осознавать ту огромную роль, которую может сыграть сотрудничество с конкурентами. Реализация этой стратегии в компании малого и среднего бизнеса в сфере туризма позволит увеличить объем ресурсов, которыми она владеет, в дополнение к экономии средств и снижению затрат за счет использования ресурсов конкурентов, что приведет к получению большей прибыли для компаний.

Необходимо отметить ряд ограничений исследования. Во-первых, выборка компаний, использованных в исследовании, относится только к Приморскому краю. Это ограничивает возможность распространения выводов, полученных в рамках исследования, на компании, работающие в других туристских дестинациях. Во-вторых, данные были собраны в единичный период времени, что не дает отследить изменения в поведении стратегического предпринимательства и сотрудничества с конкурентами «соopetition» компании и оценить этот эффект в долгосрочной перспективе. В-третьих, основные переменные модели были измерены с помощью субъективной оценки участников опроса. В будущих работах может быть проведена репликация данного исследования с помощью объективных измерений переменных. Тестирование модели исследования в условиях других дестинаций и других типов туристских компаний (рестораны, транспортные компании и т.п.) позволит повысить внешнюю достоверность полученных результатов.

\section{Сиисок источников / References}

1. Giap T. K., Gopalan S., Ye Y. Drivers of growth in the travel and tourism industry in Malaysia: A Geweke causality analysis. Economies, 2016, vol. 4, no. 3, pp. 1-15.

2. WTTC. Travel \& Tourism Economic Impact 2019 Russian Federation. London: WTTC, 2019. 
3. Buhalis D., Cooper C. Competition or co-operation? In E. Laws, B. Faulkner, G. Moscardo (Eds.), Embracing \& Managing Change in Tourism. London: Taylor \& Francis Ltd, 1998, pp. 329-351.

4. Amit R., Zott C. Value creation in e-business. Strategic management journal, 2001, vol. 22, no. 6-7, pp. 493-520.

5. Ireland R. D., Hitt M. A., Sirmon D. G. A model of strategic entrepreneurship: The construct and its dimensions. Journal of management, 2003, vol. 29, no. 6, pp. 963-989.

6. Kyrgidou L.P., Petridou E. The effect of competence exploration and competence exploitation on strategic entrepreneurship. Technology analysis \& strategic management, 2011, vol. 23, no. 6, pp. 697-713.

7. Ketchen Jr D. J., Ireland R. D., Snow C. C. Strategic entrepreneurship, collaborative innovation, and wealth creation, Strategic entrepreneurship journal, 2007, vol. 1, pp. 371-385.

8. Haugland S. A. et al. Development of tourism destinations: An integrated multilevel perspective. Annals of tourism research, 2011, vol. 38, no. 1, pp. 268-290.

9. Luo Y. A coopetition perspective of global competition. Journal of world business, 2007, vol. 42, no. 2, pp. 129-144.

10. Wang Y., Krakover S. Destination marketing: competition, cooperation or coopetition? International Journal of Contemporary Hospitality Management, 2007, vol. 20, no. 2, pp. 126-141.

11. Getz D., Carlsen J. Characteristics and goals of family and owner-operated businesses in the rural tourism and hospitality sectors. Tourism management, 2000, vol. 21, no. 6, pp. $547-560$.

12. Jaafar, M., Abdul-Aziz, A.R., Maideen, S.A., Mohd, S.Z. Entrepreneurship in the tourism industry: Issues in developing countries. International Journal of Hospitality Management, 2011, vol. 30, no. 4, pp. 827-835.

13. McGrath R. G., MacMillan I. C. The entrepreneurial mindset: Strategies for continuously creating opportunity in an age of uncertainty. Harvard Business Press, 2000, vol. 284.

14. Ahmad S. Z., Jabeen F., Khan M. Entrepreneurs choice in business venture: Motivations for choosing home-stay accommodation businesses in Peninsular Malaysia. International Journal of Hospitality Management, 2014, vol. 36, pp. 31-40.

15. Bosworth G., Farrell H. Tourism entrepreneurs in Northumberland. Annals of Tourism Research, 2011, vol. 38, no. 4, pp. 1474-1494.

16. Getz D., Petersen T. Growth and profit-oriented entrepreneurship among family business owners in the tourism and hospitality industry. International journal of hospitality management, 2005, vol. 24, no. 2, pp. 219-242.

17. Shaw G., Williams A. M. From lifestyle consumption to lifestyle production: Changing patterns of tourism entrepreneurship. Small firms in tourism. Routledge, 2013, pp. 109-124.

18. Peters M., Frehse J., Buhalis D. The importance of lifestyle entrepreneurship: A conceptual study of the tourism industry. PASOS. Revista de Turismo y Patrimonio Cultural, 2009, vol. 7, no. 3, pp. 393-405.

19. Burgelman R. A., Hitt M. A. Entrepreneurial actions, innovation, and appropriability. Strategic Entrepreneurship Journal, 2007, vol. 1, pp. 349-352.

20. Danneels E. The dynamics of product innovation and firm competences. Strategic management journal, 2002, vol. 23, no. 12, pp. 1095-1121.

21. Kotha S., Nair A. Strategy and environment as determinants of performance: evidence from the Japanese machine tool industry. Strategic management journal, 1995, vol. 16, no. 7, np. 497-518.

22. Sainaghi, R. Hotel Performance. State of the art. International Journal of Contemporary Hospitality Management, 2010, vol. 22, no. 7, pp 920-952. 
23. Kull A. J., Mena J. A., Korschun D. A resource-based view of stakeholder marketing. Journal of Business Research, 2016, vol. 69, no. 12, pp. 5553-5560.

24. Molina-Azorin J. F., Pereira-Moliner J., Claver-Cortés E. The importance of the firm and destination effects to explain firm performance. Tourism Management, 2010, vol. 31, no. 1, pp. 22-28.

25. Sainaghi R., Baggio R. Structural social capital and hotel performance: Is there a link? International Journal of Hospitality Management, 2014, vol. 37, pp. 99-110.

26. Sirmon D. G., Hitt M. A., Ireland R. D. Managing firm resources in dynamic environments to create value: Looking inside the black box. Academy of management review, 2007, vol. 32, no. 1, pp. 273-292.

27. Morris M. H., Koçak A., Ozer A. Coopetition as a small business strategy: Implications for performance. Journal of small business strategy, 2007, vol. 18, no. 1, pp. 35-56.

28. Taylor P., McRae-Williams P., Lowe J. The determinants of cluster activities in the Australian wine and tourism industries. Tourism Economics, 2007, vol. 13, no. 4, pp. 639-656.

29. Czakon W., Klimas P., Mariani M. Behavioral antecedents of coopetition: A synthesis and measurement scale. Long Range Planning, 2020, vol. 53, no. 1, pp. 101875.

30. Pesämaa $\mathrm{O}$. et al. How a learning orientation affects drivers of innovativeness and performance in service delivery. Journal of Engineering and Technology Management, 2013, vol. 30, no. 2, pp. 169-187.

31. Czernek K., Czakon W. Trust-building processes in tourist coopetition: The case of a Polish region. Tourism Management, 2016, vol. 52, pp. 380-394.

32. Zineldin, M. Co-opetition: The organisation of the future. Marketing Intelligence \& Planning, 2004, vol. 22, no. 7, pp. 780-790.

33. Kallmuenzer A., Peters M. Entrepreneurial behaviour, firm size and financial performance: the case of rural tourism family firms. Tourism Recreation Research, 2018, vol. 43 , no. 1 , pp. $2-14$.

34. Wiklund J., Shepherd D. Knowledge-based resources, entrepreneurial orientation, and the performance of small and medium-sized businesses. Strategic management journal, 2003, vol. 24, no. 13, pp. 1307-1314.

35. Shirokova G., Vega G., Sokolova L. Performance of Russian SMEs: exploration, exploitation and strategic entrepreneurship. Critical perspectives on international business, 2013, vol. 9, no. $1 / 2$, pp. 173-203.

36. Knight G. A. Cross-cultural reliability and validity of a scale to measure firm entrepreneurial orientation. Journal of business venturing, 1997, vol. 12., no. 3, pp. 213-225.

37. Pinchot, G. Intrapreneuring. Harper \& Row. New York, NY, 1985.

38. Zahra S. A. Predictors and financial outcomes of corporate entrepreneurship: An exploratory study. Journal of business venturing, 1991, vol. 6, no. 4, pp. 259-285.

39. Широкова Г. В., Ежова Я. С. Становление внутрифирменного предпринимательства в российской компании: формирование, развитие и перспективы. Российский журнал менеджмента, 2012, т. 10, №. 1. [Shirokova, G. and Yezhova, Y., Stanovlenie vnutrifirmennogo predprinimatelstva $\mathrm{v}$ rossiyskoy companii: Formirovanie, razvitie i perspectivy [Development of corporate entrepreneurship in the Russian company: the formation, development and prospects]. Rossiyskiy zhurnal menedzhmenta $=$ Russian Management Journal, 2012, vol. 10, no. 1, pp. 117-40.

40. Ireland R. D., Webb J. W. A multi-theoretic perspective on trust and power in strategic supply chains. Journal of Operations management, 2007, vol. 25, no. 2, pp. 482-497.

41. Luke B., Kearins K., Verreynne M. L. Developing a conceptual framework of strategic entrepreneurship. International Journal of Entrepreneurial Behavior \& Research, 2011, vol. 17, no.3, pp. 314-337.

42. Falshaw J. R., Glaister K. W., Tatoglu E. Evidence on formal strategic planning and company performance. Management Decision, 2006, vol. 44, no. 1, pp. 9-30. 
43. Simsek Z. Organizational ambidexterity: Towards a multilevel understanding. Journal of management studies, 2009, vol. 46, vol. 4, pp. 597-624.

44. Shane S., Venkataraman S. The promise of entrepreneurship as a field of research. Academy of management review, 2000, vol. 25no. 1, pp. 217-226.

45. Ritala P. Coopetition strategy-when is it successful? Empirical evidence on innovation and market performance. British Journal of Management, 2012, vol. 23, no. 3, pp. 307-324.

46. Ritala P., Tidström A. Untangling the value-creation and value-appropriation elements of coopetition strategy: A longitudinal analysis on the firm and relational levels. Scandinavian Journal of Management, 2014, vol. 30, no. 4, pp. 498-515.

47. Bonel E., Rocco E. Coopeting to survive; surviving coopetition. International Studies of Management \& Organization, 2007, vol. 37, no. 2, pp. 70-96.

48. Bengtsson M., Kock S. "Coopetition" in business Networks- to cooperate and compete simultaneously. Industrial marketing management, 2000, vol. 29, no. 5, pp. 411-426.

49. Ritala P., Golnam A., Wegmann A. Coopetition-based business models: The case of Amazon. com. Industrial marketing management, 2014, vol. 43, no. 2, pp. 236-249.

50. Crick, J. M., Moderators affecting the relationship between coopetition and company performance. Journal of Business and Industrial Marketing, 2018, vol. 34, no. 2, pp. $518-531$.

51. Della Corte V., Aria M. Coopetition and sustainable competitive advantage. The case of tourist destinations. Tourism Management, 2016, vol. 54, pp. 524-540.

52. Hunt S. D., Morgan R. M. The comparative advantage theory of competition. Journal of marketing, 1995, vol. 59, no. 2, pp. 1-15.

53. Bengtsson, M. and Kock, S. Cooperation and competition in relationships between competitors in business network. Journal of Business \& Industrial Marketing, 1999, vol. 14, no. 3, pp. 178-194.

54. Granata J. et al. How do micro-firms manage coopetition? A study of the wine sector in France. International Small Business Journal, 2018, vol. 36, no. 3, pp. 331-355.

55. Estrada I., Faems D., de Faria P. Coopetition and product innovation performance: The role of internal knowledge sharing mechanisms and formal knowledge protection mechanisms. Industrial Marketing Management, 2016, vol. 53, pp. 56-65.

56 . Velu C. Evolutionary or revolutionary business model innovation through coopetition? The role of dominance in network markets. Industrial Marketing Management, 2016, vol. 53, pp. 124-135.

57. Bouncken R. B., Kraus S. Innovation in knowledge-intensive industries: The doubleedged sword of coopetition. Journal of Business Research, 2013, vol. 66, no. 10, pp. 2060-2070.

58. Walley K. Coopetition: an introduction to the subject and an agenda for research. International Studies of Management \& Organization, 2007, vol. 37, vol. 2, pp. 11-31.

59. Avci U., Madanoglu M., Okumus F. Strategic orientation and performance of tourism firms: Evidence from a developing country. Tourism Management, 2011, vol. 32, no. 1, pp. $147-157$.

60. Dawes J. Do data characteristics change according to the number of scale points used? An experiment using 5-point, 7-point and 10-point scales. International journal of market research, 2008, vol. 50, no. 1, pp. 61-104.

61. Podsakoff P. M., MacKenzie S. B., Podsakoff N. P. Sources of method bias in social science research and recommendations on how to control it. Annual review of psychology, 2012, vol. 63, pp. 539-569.

62. Barney J. B. Is the resource-based "view" a useful perspective for strategic management research? Yes. Academy of management review, 2001, vol. 26, no. 1, pp. 41-56.

63. Teece D. J., Pisano G., Shuen A. Dynamic capabilities and strategic management. Strategic management journal, 1997, vol. 18, no. 7, pp. 509-533. 
64. Alvarez S. A., Busenitz L. W. The entrepreneurship of resource-based theory. Journal of management, 2001, vol. 27, no. 6, pp. 755-775.

65. Tajeddini K. Effect of customer orientation and entrepreneurial orientation on innovativeness: Evidence from the hotel industry in Switzerland. Tourism management, 2010, vol. 31, no. 2, pp. 221-231.

66. Zott C. Dynamic capabilities and the emergence of intraindustry differential firm performance: insights from a simulation study. Strategic management journal, 2003, vol. 24 , no. 2 , pp. $97-125$.

67. Sirmon D. G., Hitt M. A. Managing resources: Linking unique resources, management, and wealth creation in family firms. Entrepreneurship theory and practice, 2003, vol. 27, no. 4, pp. 339-358.

68. Girod S. J. G., Whittington R. Reconfiguration, restructuring and firm performance: Dynamic capabilities and environmental dynamism. Strategic Management Journal, 2017, vol. 38, no. 5, pp. 1121-1133.

69. Vernon J. et al. Collaborative policymaking: Local sustainable projects. Annals of Tourism research, 2005, vol. 32, no. 2, pp. 325-345.

\section{Сведения об авторах / About authors}

Хасан Ага Муханад, аспирант, кафедра менеджмента, Школа экономики и менеджмента, Дальневосточный федеральный университет. 690022 Россия, г. Владивосток, о-в Русский, кампус ДВФУ, корпус G. E-mail: agha.muhanad@gmail.com

Hasan Agha Muhanad, Postgraduate Student, Department of Management, School of Economics and Management, Far Eastern Federal University. Building G, FEFU campus, Russky Island, Vladivostok, Russia 690922. E-mail: agha.muhanad@gmail.com

Гаффорова Елена Борисовна, доктор экономических наук, доцент, профессор кафедры менеджмента, директор Школы экономики и менеджмента, исследователь научноисследовательской лаборатории «Лаборатория исследования предпринимательства», Дальневосточный федеральный университет. 690920 Россия, г. Владивосток, о-в Русский, кампус ДВФУ, корпус G, каб. G609.E-mail: gafforova.eb@dvfu.ru

Elena B. Gafforova, Doctor of Economic Sciences, Associate Professor, Professor, Department of Management, Director, School of Economics and Management, Researcher, the Research Laboratory "Laboratory of Entrepreneurship Research", Far Eastern Federal University. Office G609, Building G, FEFU campus, Russky Island, Vladivostok, Russia 690920.E-mail: gafforova.eb@dvfu.ru 